\title{
Da história das disciplinas escolares à história da cultura escolar: uma trajetória de pesquisa
}

\author{
Eurize Caldas Pessanha \\ Maria Emília Borges Daniel \\ Maria Adélia Menegazzo
}

Universidade Federal de Mato Grosso do Sul

\section{Introdução}

Pesquisando dentro do campo conhecido como história das disciplinas escolares desde 1993, o grupo de pesquisadores ao qual estão ligadas as autoras deste $\operatorname{artigo}^{1}$ já investigou a história de várias disciplinas:

1 Ao longo desses dez anos, o grupo de pesquisa "Professores e Disciplinas Escolares" recebeu financiamentos da PróReitoria de Pesquisa e Pós-Graduação da Universidade Federal de Mato Grosso do Sul, do CNPq (bolsas PIBIC e Produtividade em Pesquisa e de Auxílio Integrado de Pesquisa) e da CAPES (bolsa de pós-doutorado). Ao longo dos trabalhos realizados, sofreu alterações na sua formação, tendo contado com a participação, além das autoras deste artigo, de mestrandos do Programa de Pós-Graduação em Educação da UFMS: Carla Z. Maluf de Araújo (1995-1996), Júlio da Costa Feliz (1996-1998), Maria Cristina Lanza de Barros (1996-1998), Maria de Fátima Viegas Josgrilbert (1996-1998), Pedro Rauber (1996-1998), Elisângela Alves da Silva (1996-1998), Ana Paula Mancini (1996-1998), Glauce Soares Casimiro (2001-2003); professores pesquisadores: Horácio Braga (1998-2003), Fabiany de Cássia Tavares Silva (2003); alunos do desde disciplinas básicas dos cursos de Formação de Professores, como didática e prática de ensino, até disciplinas consideradas estratégicas como canto orfeônico, geografia, educação moral e cívica, e as disciplinas língua portuguesa e língua inglesa. Através de um projeto de pesquisa intitulado "As disciplinas escolares como forma de analisar a educação na escola", ${ }^{2}$ analisou a materialização do modo de pensar e de formar os indivíduos de uma comunidade, as

curso de pedagogia da UFMS: Rosimeri da Silva Pereira (20002002), Elaine Cristina Ferreira D’Ávila (2000), Mariceli Ferreira Gutierres (2000); bolsistas de Aperfeiçoamento de Pesquisa/CNPq: Kelly Glay da Silva Sena Sakihama e Maria Helena Santana Reis (1997-1998); bolsistas de Iniciação Científica PIBIC/CNPq: Sheila Denise Guimarães e Alessandra Fernandes B. Moroni (1997-1998), Débora Eiko Batista Takeuchi, Patrícia Menegheti e Denise Lamb (2002/2003), Jane Ferreira dos Santos e Kátia Costa (2002/2003); pesquisadora colaboradora: Paula Martini (1998). As autoras agradecem às instituições e, principalmente, às pessoas citadas.

2 Projeto de pesquisa financiado pela Universidade Federal de Mato Grosso do Sul, concluído em 2003. 
maneiras de receber, filtrar e reorganizar os dados da cultura sempre subjacente aos projetos pedagógicos, para encontrar mediadores da construção da memória histórica, procurando compreender os processos e projetos culturais que aí estão envolvidos e incorporar à análise das disciplinas escolares a análise da história da cultura que as produziu e que vem sendo produzida por elas. O objetivo deste artigo é refletir sobre a trajetória de pesquisa que este grupo vem percorrendo e sobre como, partindo de pesquisas sobre a história das disciplinas escolares, foi levado ao estudo da história da cultura escolar como um caminho para analisar a história do currículo.

Nossa proposta de pesquisa concebe a escola como o lócus dessa história, isto é, o espaço e o tempo em que as disciplinas escolares se construíram historicamente. Mais do que apenas entender esses processos, o que se vem buscando é situá-los dentro do movimento da cultura escolar no Brasil (Pessanha, 2003; Menegazzo, 2001).

Embora cultura escolar não seja um conceito simples de delimitar, considera-se que na escola foram sendo historicamente construídas normas e práticas definidoras dos conhecimentos que seriam ensinados e dos valores e comportamentos que seriam inculcados, gerando o que se pode chamar de cultura escolar. Conhecimentos, valores e comportamentos que, embora tenham assumido uma expressão peculiar na escola, e, principalmente, em cada disciplina escolar, são produtos e processos relacionados com as lutas e os embates da sociedade que os produziu e foi também produzida nessa e por essa escola.

\section{História das disciplinas escolares}

Segundo Chervel (1990), a prática escolar fornece informações sobre a produção do conhecimento que não são encontradas no nível de sua produção dentro da ciência ou em outras instâncias da sociedade. Essa constatação fez com que seus estudos se dirigissem para a investigação da história das disciplinas escolares que lida com fontes primárias, como, por exemplo, os manuais didáticos e os cadernos escolares, com milhões de páginas escritas que, segundo ele, podem revelar uma história ainda não relatada nem analisada.

A palavra disciplina, tal como se conhece hoje, é uma criação recente. Na França, por exemplo, só é registrada após a Primeira Guerra Mundial, mas guarda a idéia de sua origem: disciplinar, ordenar, controlar. A disciplina escolar seria resultado da passagem dos saberes da sociedade por um filtro específico, a tal ponto que, após algum tempo, ela pode não mais guardar relação com o saber de origem. Para Chervel (1990), a disciplina é o preço que a sociedade paga à cultura para passá-la de uma geração à outra.

Fica claro, portanto, que o referencial epistemológico desse campo de investigação sustenta que as disciplinas escolares não são reflexo, vulgarização ou adaptação pura e simples das ciências de referência.

À medida que a história de uma disciplina se desenrola, sofre transformações no seu interior, as quais dificultam a análise de sua relação com a sociedade, dando a impressão de que só os seus fatores internos, ou aqueles relacionados com a sua ciência de referência, foram responsáveis pela sua história. Encontrar os pontos principais desse processo, considerando as forças e os interesses sociais em jogo na história de determinadas disciplinas, pode lançar mais luz sobre seus conteúdos e suas práticas com o objetivo de, se necessário, modificá-los para atender a novas necessidades, em vez de reproduzi-los como se fossem neutros e independentes.

Mais especificamente, é preciso analisar a constituição de uma disciplina escolar como "produto e processo que impõem significado às práticas humanas" (Menegazzo, 2001), isto é, como cultura. Nesse sentido, é preciso incorporar a essa discussão não apenas um número cada vez maior e diversificado de disciplinas, mas, principalmente, ampliar a discussão dessas histórias, incorporando a discussão sobre a cultura que as produziu e é produto delas.

Torna-se necessário, por exemplo, analisar o processo que levou à introdução e à posterior eliminação da disciplina língua latina dos currículos escolares, depois de ter sido considerada uma disciplina-chave na formação das mentes; o processo de substituição 
dos manuais de língua e civilização francesa pelos manuais instrumentais de língua francesa; como o ensino de língua inglesa seguiu a trajetória de estudo de textos à aquisição de habilidades discursivas, passando pelo treinamento mecânico de estruturas básicas; como o ensino de língua portuguesa deixou de ser o ensino da gramática "que sistematizava e descrevia a língua consagrada pelos escritores representantes dessa tradição, mas também devia enriquecer o espírito da mocidade com o legado respeitável da boa e velha linguagem colhida nos provérbios populares e com a influência edificante dos princípios morais, que eles contêm", e chegou à virada pragmática a que se assiste agora (Daniel, 2001).

Chervel (1990) propõe algumas questões como ponto de partida para essa análise: Qual a concepção de conhecimento daquela sociedade (delimitar: uma cidade, um grupo social)? Qual a sua concepção de diferenças culturais? Isto é, quem é o outro que precisa ser educado? Qual a sua concepção de professor? Isto é, quem eram, como eram contratados e formados e o que se exigia dos professores? Quem era excluído/ incluído por essa cultura? Que instrumentos eram indicados para o professor? Como eles eram usados?

As respostas a essas questões, mesmo sendo a base para o trabalho empírico sobre a história das disciplinas escolares, precisam ser analisadas como processos e produtos das práticas escolares, isto é, da cultura escolar.

\section{Da história das disciplinas escolares à história da cultura escolar}

Faria Filho (1996), ao descrever a história da educação da cidade de Belo Horizonte, afirma que, no início de sua história, a cultura escolar era igual à cultura da população. Com a criação dos grupos escolares, em substituição às escolas isoladas, criou-se não apenas um lugar físico diferente, mas, principalmente, um novo lugar simbólico, capaz de operar uma mudança de sensibilidade, linguagem, comportamentos, costumes, e mesmo de projetos e perspectivas sociais, a começar pelas crianças. No grupo escolar, agora um lócus, a escola deixou o espaço privado para entrar no público, espaço de construção da cultura escolar.

As pesquisas sobre a história da educação pública no Brasil vêm revelando que a escola (física e simbolicamente) foi consolidando-se como o lugar mais apropriado para a formação das novas gerações. Nela foi sendo construída uma cultura escolar distante da cultura de parcelas da população que se pretendia modificar através das crianças: uma cultura escolar que não se articula em torno do conhecimento, mas da possibilidade de criar uma instituição ordenadora da vida social (Faria Filho, 1996). Foi principalmente durante as três primeiras décadas do século XX que este processo ficou mais claro nas escolas brasileiras.

Embora historiadores da educação no Brasil venham alertando, há algum tempo, para a tendência, que acabou proliferando entre os novos historiadores da educação, de privilegiar a década de 1930 como a década inaugural de todas as iniciativas na área, é preciso registrar que essa foi a década das inaugurações: de ministérios, institutos, órgãos, leis orgânicas e outros dispositivos que tiveram a tarefa mais do que simbólica de evidenciar um discurso de que se estava fazendo a revolução e a civilização do Brasil, tal como a República, que tentou instituir a ordem por decretos (Carvalho \& Nunes, 1990).

No caso específico da educação, o livro de Romanelli (1983), História da educação brasileira, parece ter contribuído para a consolidação da percepção de 1930 como marco divisório de um período caótico para um período de organização, uma vez que sua coletânea de leis da educação, gestadas ou produzidas na década de 1930, foi organizada a partir dessa hipótese. Uma análise histórica mais profunda levanos a concluir com De Decca (1988) que 1930 começou, no mínimo, em 1928, isto é, ao escrever a história a partir do silêncio dos vencidos, o autor mostra como os processos que culminaram com o período conhecido como pós-revolução de 1930 apresentam raízes nas lutas travadas na década anterior.

Como disse Antonio Candido, "o movimento de outubro [1930] não foi um começo absoluto nem uma 
causa primeira e mecânica, porque na história não há dessas coisas" (1989, p. 181). O mesmo autor, testemunha participante desses acontecimentos, nos diz:

Quem viveu nos anos 30 sabe qual foi a atmosfera de fervor que os caracterizou no plano da cultura sem falar de outros. [...] foi um eixo e um catalisador: um eixo em torno do qual girou de certo modo a cultura brasileira, catalisando elementos dispersos para dispô-los numa configuração nova. [...] Os anos 30 foram de engajamento político, religioso e social no campo da cultura. (p. 181-182)

A busca da origem de algumas das disciplinas escolares já estudadas no Brasil chegou sempre aos anos de 1930 como marco importante. Quer como momento de consolidação, como foi o caso da geografia, que "encontra nesse contexto histórico [anos de 1930] o palco ideal para se desenvolver cientificamente e se consolidar enquanto disciplina escolar" (Barros, 2000, p. 10), da didática que aparece nos currículos em meados da década, e da disciplina canto orfeônico, uma das disciplinas estratégicas ${ }^{3}$ do Estado Novo; quer como momento de profundas inflexões, como na história da disciplina moral e cívica, exatamente por ter sido excluída dos currículos escolares nesse período (Josgrilbert, 1998). Ou como período de gestação de experiências que se consolidariam na década seguinte, como aconteceu com a disciplina prática de ensino, antes ministrada na forma de exercícios práticos, e que só foi caracterizar-se como disciplina escolar, com conteúdo, professor e horário definidos, com a Lei Orgânica do Ensino Normal, em 1946 (Rauber, 1999).

Se no final do século XIX a construção da ordem e a salvação das almas não exigiam dos professores nada que eles já não soubessem de berço, dispensando cursos de formação, provas sobre como ensinar ou a disciplina didática (Pessanha, 2000), na década de

3 Considera-se disciplina estratégica aquela cujos documentos legais explicitam os objetivos políticos de sua inclusão no currículo.
1930 pelo menos parte da sociedade parece ter assumido a posição de que era preciso dar uma resposta convincente, ordenadora, ao movimento renovador dos anos de 1920, durante os quais a direção do desenvolvimento no Brasil apresentou algumas possibilidades que provocavam temor nas "elites" (Ianni, 1989).

A promulgação de leis, decretos e outros instrumentos legais com o objetivo de organizar a educação no Brasil; a inclusão de algumas disciplinas estratégicas como canto orfeônico e a direção que se procurou dar a outras disciplinas parecem ter sido uma tentativa de ordenação e outra de colocar em prática a inserção da escola no processo de ajustamento dos indivíduos à sociedade, isto é, na direção que o movimento vitorioso em 1930 havia escolhido.

Afirmar que a escola da época foi o reflexo dessas tentativas de ordenação e inculcação, e que a introdução da didática nos cursos de formação de professores, exatamente na década de 1930, tivesse sido a resposta das elites a esse temor, seria negar a especificidade dos processos sociais que se desenrolam na escola e a própria existência de uma cultura escolar.

No entanto, a análise da configuração da disciplina, durante os anos 30 do século XX, e dos manuais de didática evidenciou como se tentou impor a marca da ordem e do controle (Araújo, 1997). Em contrapartida, a criação da disciplina canto orfeônico, considerada explicitamente uma disciplina estratégi$c a$, sob a inspiração e regência de Villa-Lobos, teve como objetivo realizar com a música o que as tropas não haviam conseguido: unir multidões de brasileiros cantando a uma só voz, seguindo as instruções de um maestro (Feliz, 1998).

A história dessa disciplina apresenta características bem instigantes: embora a documentação analisada revele a existência de, pelo menos, duas posições conflitantes em relação ao ensino de canto orfeônico, apenas uma delas, a de Villa-Lobos, ${ }^{4}$ oficial e oficiali-

\footnotetext{
4 Vale lembrar que Villa-Lobos é um dos exemplos mais
} marcantes da cooptação de intelectuais que, de vanguarda nos anos 20 do século XX, passaram a oficiais, sofrendo o processo que 
zada, parece ter sido colocada em prática nas escolas públicas. Segundo as análises de Feliz (1998), a escolha dos ritmos e andamentos musicais das obras recomendadas às escolas parecia obedecer a um padrão que induzisse à disciplina do corpo; assim, por exemplo, a escolha do andamento dois por quatro, associado ao andar, à marcha, seria destinada a regular ou acompanhar os movimentos de grande número de pessoas, principalmente em sentido militar.

Nesse sentido, as peças escolhidas não deveriam apresentar dificuldade para os cantores, deveriam ser simples, sem acidentes, sempre iniciando com a primeira voz e a segunda entrando em forma de cânones. Feliz (1998) também chama a atenção para uma das marchas encontradas no manual de canto orfeônico dirigido aos professores. A Marcha Escolar, destinada a acompanhar a ida ao recreio, apresenta uma letra que fala em alegria, recreio:

Todos em alas/ Como bons soldados/ Bem perfilados/ De cabeça erguida,/ Posição correta,/ Vamos dois a dois/ Em linha certa,/ Todos aprumados,/ E bem ritmados, / Caminhemos, pois!/Todos em fila,/ Num alegre bando,/ À voz do comando,/ Marchemos, assim!/ No campo aberto,/ como é bom a gente/ Ir livremente,/ Recrear, enfim!/ Vamos colegas,/ Findo é o estudo/ Esqueçamos tudo/Vamos recrear/ Já marchar, marchar!/ Todos alerta.

A reconstituição da história da disciplina geografia no Brasil, realizada por Barros (2000), mostrou como tal disciplina também adquiriu uma função estratégica durante o Governo Vargas na divulgação e na consolidação de sua política nacionalista, quando a geografia, dentro e fora da escola, atinge seu momento de maior peso e influência junto ao Estado e à sociedade brasileira.

Sem pretender esgotar as possibilidades de análise que a história dessas disciplinas oferece, e consi-

Antonio Candido (1964) chamou de normalização e rotinização do que antes parecia estranho e de vanguarda, e que era preciso combater. derando os riscos de reducionismo dessas análises, percebe-se em suas histórias traços de uma sociedade que tinha a ordem e a disciplina como valores, pelo menos entre as frações de classe que a dirigiam. Valores a serem preservados e cultivados tanto na formação dos professores quanto nas disciplinas escolares. Provavelmente para se contrapor à "desordem" e à "anarquia" dos anos loucos, dos anos de 1920, quando foi possível o surgimento de movimentos anarquistas, comunistas e modernistas, cabia agora "oficializar", "normalizar", "rotinizar", ou reprimir sumariamente, para que nada saísse dos trilhos, para usar uma metáfora bem cara à época: a de que a sociedade devia "entrar nos trilhos" do progresso como as locomotivas (Candido, 1964).

A análise sistematizada dos resultados das pesquisas sobre a história das disciplinas escolares, realizadas durante os dez anos de existência do grupo, conduziu à conclusão de que o estudo da história das disciplinas escolares estaria limitado caso se restringisse apenas aos processos ocorridos internamente em cada disciplina.

À medida que se aprofundava a análise das histórias das disciplinas escolares pesquisadas, a "noção de cultura escolar" 5 foi possibilitando articular essas histórias, e a história da cultura escolar tornou-se o objeto de pesquisa do grupo.

\section{Cultura e escola}

A origem da "noção de cultura escolar" na qual os trabalhos do grupo se fundamentam está, obviamente, baseada nas concepções de cultura que assume. Termo polissêmico, a palavra cultura vem sofren-

5 Ao colocar entre aspas e usar propositadamente uma expressão tão vaga como noção, estamos querendo enfatizar que não consideramos cultura escolar um instrumento de análise, por se tratar de um conceito fluido, e que qualquer tentativa de operacionalizá-lo pode destruir suas implicações teóricas e reduzir a análise da escola à procura de elementos isolados que a descrevam apenas na superfície. 
do desgaste de sua utilização em diferentes sentidos e na própria dificuldade de explicitá-la.

Williams (1992) considera o termo cultura em dois sentidos. No sentido antropológico/sociológico, define o modo de vida global e o sistema de significações de um determinado grupo; no sentido mais especializado, inclui a produção intelectual e as práticas significativas (artes, linguagem, filosofia, moda, publicidade...). Essa idéia aponta para o entendimento da cultura como um sistema de significações realizado, voltado a abrir "[...] espaço para o estudo de instituições, práticas e obras manifestamente significativas, mas não apenas isso, também para, por meio dessa ênfase, estimular o estudo das relações entre essas e outras instituições, práticas e obras" (p. 207-208).

Certeau $(1995,1998)$ analisa cultura como as práticas das pessoas comuns, as maneiras de fazer que, majoritárias na vida social, não aparecem muitas vezes senão a título de resistência ou inércia em relação ao desenvolvimento da produção sociocultural; uma ciência prática do singular que faz dos espaços público e privado um lugar de vida possível. Um pouco mais explícito, Geertz (1978) considera cultura o tecido de significados, expectativas e comportamentos, discrepantes ou convergentes, que um grupo humano compartilha e constrói socialmente.

Estudioso da cultura escolar, Viñao-Frago descreve cultura como um "[...] mundo humanamente construído, mundo das instituições e dos signos no qual, desde a origem, se banha o indivíduo humano, tão-somente por ser humano, e que constitui como que sua segunda matriz" (apud Viñao-Frago \& Escolano, 1998, p. 168).

Considerando que a noção de significado constitui o elemento fundamental do conceito de cultura, este grupo concebe cultura como produto e processo que impõe significado às práticas humanas, conceito adotado já há algum tempo, e que tem permitido ampliar a visão sobre os bens culturais e seus modos de produção. É nesse sentido, também, que é possível se libertar das visões limitadas que só compreendem como cultura aquela chamada erudita e afeita às belas-artes, em detrimento dos outros modos de expressão (Menegazzo, 2001).

Elemento fundante para o espírito de modernidade, um dos principais motores de triunfo da modernidade (Pineau, 1999, p. 39), a escola tornou-se o local de transmissão de saberes, símbolos e valores.

Nesse sentido, a escola é sempre analisada como lugar de cultura, como lugar de formação, de reprodução dos valores da sociedade. Williams, no entanto, chama a atenção para o fato de que "a metáfora da 'reprodução', se forçada em demasia, pode dissimular os processos essenciais de autonomia relativa e de mudança, mesmo enquanto insista de maneira conveniente em um caráter geral e intrínseco" (Williams, 1992, p. 184).

Na mesma direção, Antonio Candido (1971), com base nos estudos de Gurvitch, aponta que, numa perspectiva macrossociológica, “[...] a própria vida interna da escola [...] reelabora, segundo a sua dinâmica interna, as normas, valores, práticas comunitárias, dandolhes uma coloração nova, mas nem por isso alheia ao encadeamento geral da sociedade [...]" (p. 128).

Parece claro, portanto, que há uma especificidade na vida interna da escola que autoriza a análise de uma cultura escolar, mas que o uso da expressão $\mathrm{cul}$ tura escolar não implica considerar a existência de uma cultura oposta ou desvinculada da cultura da sociedade que a produziu e foi por ela produzida.

\section{Cultura escolar como objeto histórico}

O conceito de cultura escolar aparece sempre relacionado com um espaço ${ }^{6}$ destinado/privilegiado para transmissão de conhecimentos e, principalmente, valores em determinado tempo (Forquin, 1993; Faria Filho, 1996; Julia, 2001; Viñao-Frago \& Escolano, 1998; Viñao-Frago, 2000; Silva, 2003).

6 As origens das palavras disciplina e didática parecem trazer também a idéia de espaço, pátio onde se reuniam estudantes, ou lugares (livros, estantes) onde se reuniam as idéias (Hamilton, 2001). 
Nesse espaço foi constituindo-se a cultura escolar, através das normas e práticas que definiam os valores e comportamentos que seriam impostos e os conhecimentos a serem ensinados.

No entanto, se o espaço, ou seja, o lócus, é o território comum para analisar a cultura escolar, a sua definição como objeto de conhecimento não é tão simples.

Para Julia (2001):

[...] poder-se-ia descrever a cultura escolar como um conjunto de normas que definem conhecimentos a ensinar e condutas a inculcar, e um conjunto de práticas que permitem a transmissão desses conhecimentos e a incorporação desses comportamentos; normas e práticas coordenadas a finalidades que podem variar segundo as épocas (finalidades religiosas, sociopolíticas ou simplesmente de socialização). (p. 10)

Considerando que a cultura escolar não se articula em torno do conhecimento, mas da possibilidade de construção de uma instituição (Faria Filho, 1996) cuja construção esteve freqüentemente associada a um projeto político e à noção de progresso (Julia, 2001), estudar a cultura escolar é estudar os processos e produtos das práticas escolares, isto é, práticas que permitem a transmissão de conhecimentos e a imposição de condutas circunscritas à escola.

Parece claro, portanto, que ver a cultura escolar como objeto histórico implica analisar o significado imposto aos processos de transmissão de saberes e inculcação de valores dentro desse espaço. Implica também definir a transmissão como elemento central desse processo, tendo-se cuidado de não fazer exclusivamente uma análise ideológica (idem).

Segundo o mesmo autor, a constituição de uma cultura escolar exigiu três elementos essenciais: um espaço específico, cursos graduados em níveis e corpo profissional próprio. Esses elementos constituem a base para a análise das práticas que permitiram a transmissão de conhecimentos e a inculcação de condutas e valores.

A análise da história da cultura escolar fundamentase, como qualquer história cultural, na história de três elementos indissociáveis: os objetos em sua materiali- dade, as práticas e as configurações dos dispositivos e das suas variações. ${ }^{7}$ Elementos que podem ser recuperados apenas quando se vai às fontes primárias.

Para analisar a cultura escolar, é preciso analisar o conjunto das normas e práticas definidoras dos conhecimentos que aquela sociedade desejava que fossem ensinados, e os valores e comportamentos a serem impostos. Esses elementos nem sempre são visíveis nos registros oficiais (relatórios, atas, boletins). Muitas vezes, é preciso ler esses registros de forma diferente, além de procurar outros menos formais, como: cadernos, planos de ensino, livros, provas e material didático em geral.

Constituem fontes privilegiadas para a análise da cultura escolar: cadernos, exercícios, planos de ensino, provas e exames, manuais didáticos, relatórios de inspetores. Importando sempre analisar se, como e por quem eles foram usados, procurando as respostas para as questões levantadas. Essas fontes não são utilizadas freqüentemente na historiografia tradicional: livros, cadernos escolares, provas, exames, fotos de formatura, boletins escolares, planos de ensino, atas escolares, diplomas, relatórios e depoimentos que, normalmente, não são mantidos nem conservados nos arquivos públicos.

Nunca é demais enfatizar que a pesquisa histórica se alimenta de registros depositados em arquivos nem sempre organizados, nem sempre preservados, cabendo aos pesquisadores reconstituir práticas sociais não mais presentes ou ressignificadas nos dias atuais. As fontes primárias constituem, assim, o elemento mais importante para esclarecer lacunas de documentos, de memória, ou mesmo para alterar estereótipos cristalizados e reproduzidos ad aeternum através da utilização apenas de fontes secundárias.

Como depositárias de fontes primárias, as escolas constituem praticamente um manancial pouco explorado. As sucessivas legislações delegaram aos colégios alguns poderes cartoriais, obrigando-os a man-

\footnotetext{
7 A esse respeito ver Carvalho e Nunes (1993) e Valente
} (2001). 
ter sob sua guarda documentos que, embora tenham adquirido um caráter de registro legal, podem trazer elementos fundamentais para se analisar as práticas escolares. Livros de atas, cadastro e termo de posse de professores, boletins, diários de classe, pastas individuais de alunos, registro de provas orais e escritas, são alguns dos documentos que as escolas eram obrigadas a manter como comprovantes. Embora um certo furor desburocratizante tenha levado muitas escolas a incinerarem, a partir da década de 1980, com amparo legal, seus arquivos e, mais recentemente, a informatização tenha alterado as formas de arquivar documentos, algumas escolas ainda mantêm registros importantes para a história da cultura escolar.

Se à escola cabia a guarda de documentos oficiais, nem sempre é possível encontrar fontes nãooficiais como as provas mensais, os planejamentos dos professores, os cadernos escolares, a não ser quando, por alguma pendência jurídica, eles se tornavam oficiais, como no caso de transferências.

Os cadernos, ${ }^{8}$ por exemplo, são instrumentos usados pelos alunos desde o século XVI e chamados de "livro branco" no Ratio Studiorum. Mais recentemente, uma pesquisa realizada na França pelo Institut National de Recherche Pédagogique (INRP) mostrou que dentro de duas classes pelo menos uma utilizava cadernos desde, pelo menos, 1883, mesmo em escolas consideradas reacionárias para a época (Hébrard, 2001). O autor considera que "o caderno, tanto por sua inserção na história da escola quanto pela preocupação de conservação da qual ele é objeto, é certamente um testemunho precioso do que pode ter sido e ainda é o trabalho escolar de escrita" (p. 121).

Embora não haja nenhuma indicação sobre a conservação institucionalizada de cadernos escolares no Brasil, como ocorre na França, pesquisas como as de Araújo (1997) já localizaram cadernos escolares bem conservados em arquivos pessoais, que se constituíram em valiosa fonte de pesquisa.

8 Em sua origem etimológica, do latim quatternus, guarda relação com quattor, quatro em latim, indicando o número de folhas desse objeto (Gvirtz, 1995).
Gvirtz (1995), baseando-se em Foucault, considera que, enquanto dispositivo escolar, os cadernos são um conjunto de práticas discursivas escolares que se articulam de um determinado modo, produzindo um efeito. Esse discurso, produzido na e pela escola, mais do que um dispositivo escolar, constitui um dos processos e produtos mais significativos das práticas escolares, isto é, práticas que permitiram a transmissão de conhecimentos e a imposição de condutas circunscritas ao espaço escolar.

Ao lado dos cadernos, livros, relatórios, atas e outras fontes, oficiais ou não, a constituição do espaço físico da escola também se constitui em importante fonte para a história da cultura escolar.

Os edifícios escolares, como qualquer outro edifício, constituem-se como lócus à medida que seus ocupantes experimentam e interpretam esse espaço e dele apropriam-se, atribuindo-lhe significados e valores. Assim, a forma não apenas determina o uso e a experiência, mas também é igualmente determinada pelos dois na medida em que é interpretável e, portanto, pode ser influenciada (Hertzberger, 1996). Desse modo, o homem imprime, primeiro, um caráter individual nos edifícios que constrói, através do uso de determinado material, forma e outras qualidades, e, então, são esses atributos que passam a exercer sua influência sobre o homem, ou seja:

\footnotetext{
[...] sua capacidade de absorver e comunicar significado determina o efeito que a forma pode ter sobre os usuários, e, inversamente, o efeito dos usuários sobre a forma [...]. Como as palavras e as frases, as formas dependem do modo como são "lidas" e das imagens que são capazes de suscitar para o "leitor" [...]. A capacidade de absorver significados e também de abandoná-los sem mudar essencialmente, faz da forma um portador potencial de significado - em suma, significável [...]. (Hertzberger, 1996, p. 150)
}

Assim, a produção do espaço escolar, como de qualquer outro espaço arquitetônico, se faz baseada em uma linguagem decodificada a partir dos sentidos, capaz de constituir um discurso que fala sobre o seu usuário, e, concomitantemente, dialoga com ele. 
Viñao-Frago (2000) também considera que:

\author{
[...] esses lugares e tempos são determinados e determinam \\ uns ou outros modos de ensino e aprendizagem. [...] Em \\ síntese, o espaço e o tempo escolares não só conformam o \\ clima e a cultura das instituições educativas, mas também \\ educam. (p. 99, tradução nossa)
}

Espaço e tempo constituem, assim, os dois elementos-chave para a compreensão da cultura escolar.

\section{À guisa de conclusão, uma proposta de pesquisa sobre cultura escolar}

Nessa direção, as pesquisas desenvolvidas atualmente pelo grupo vêm tendo como objetivo a análise da história da cultura escolar na cidade de Campo Grande, Mato Grosso do Sul.

Embora o ensino público em Mato Grosso/Mato Grosso do Sul já tenha sido objeto de importantes pesquisas $^{9}$ cujos resultados servem de base para analisar a sua história, as pesquisas a respeito da história do ensino em Campo Grande, além de escassas, não focalizam a cultura escolar como seu objeto. Mesmo as pesquisas realizadas no âmbito deste grupo sobre a história das disciplinas didática e língua portuguesa, apesar de localizarem a história dessas disciplinas no âmbito de escolas de Campo Grande, são mais descritivas e apenas fornecem pistas para a análise da história da cultura escolar nesta cidade (Araújo, 1997; Daniel, 2001).

Segundo os historiadores, a história da educação escolar em Campo Grande começou a ser escrita em 1895, com um abaixo-assinado para angariar fundos destinados a auxiliar o professor José Rodrigues Benfica, gaúcho que participara da guerra contra o Paraguai, para que ele continuasse seu ofício como

9 Para citar apenas algumas: Saboya Filho (1993), Araújo (1997), Alves (1984), Bittar (1999), Corrêa (1995), Rodrigues (1988), Alves (1998), Correia Filho (1969) e Marcílio (1963). primeiro mestre-escola da região (Bittar \& Ferreira Jr., 1999). No entanto, há registro de reclamações de seus representantes de que o desenvolvimento da educação, ao sul do estado de Mato Grosso, não figurava entre as prioridades dos governos estaduais. ${ }^{10}$ Motivo que levou Arlindo de Andrade, quando intendente, a enfrentar a administração estadual e contratar a construção do primeiro Grupo Escolar da cidade, situado na avenida Afonso Pena, transformado, posteriormente, na escola primária mais famosa da cidade: a Escola Joaquim Murtinho.

O ensino secundário, objeto de desejo da classe média em ascensão (Sposito, 1984, 1993; Pessanha, 1994), foi inicialmente ministrado apenas em escolas particulares: dois colégios católicos - um masculino, o Colégio Dom Bosco, outro feminino, o Colégio Auxiliadora, fundado em 1926 - e uma escola não-confessional, o Colégio Oswaldo Cruz, aberta na mesma década.

A origem do Colégio Dom Bosco foi o Instituto Pestalozzi, fundado em Aquidauana, em 1915, por Arlindo Lima, transferido para Campo Grande em 1917, passando a se chamar Ginásio Municipal de Campo Grande (por ser subvencionado pela prefeitura). A Missão Salesiana adquiriu a escola em 1930, mudando seu nome para Ginásio Municipal Dom Bosco. Reconhecido por decreto federal de 1934, passou a ser denominado Colégio Dom Bosco, em 1948, através de outro decreto federal.

Em 1939, Maria Constança Barros Machado propôs ao interventor Júlio Muller e ao doutor João Ponce de Arruda, secretário de Fazenda do Estado, a criação de um ginásio estadual que pudesse resolver os

\footnotetext{
${ }^{10}$ Paulo Coelho Machado registra que, com cerca de dez mil
} habitantes, em 1921, a cidade contava apenas com seis estabelecimentos estaduais com 197 alunos; três municipais, com 67 alunos; dois colégios particulares, além do Instituto Pestalozzi, subvencionado pela municipalidade, com 306 alunos; a Escola Republicana, com 157; e onze escolas primárias particulares, espalhadas pela campanha, com 206 alunos. Na cidade, a freqüência total era de 727 alunos (cf. Bittar \& Ferreira Jr., 1999). 
problemas dos que precisavam continuar a estudar e não tinham meios de pagar a escola (Machado apud Rosa, 1990).

O primeiro ginásio público foi instalado em 1939, como resultado de mobilização política dirigida pela professora cuiabana ${ }^{11}$ Maria Constança Barros Machado, que hoje dá nome à escola que fundou.

As famílias brigavam para colocar seus filhos nessa escola (Bittar \& Ferreira Jr., 1999), que, inaugurada com o nome de Liceu Campo-Grandense, funcionou no mesmo prédio do Joaquim Murtinho, tendo mudado de nome para Ginásio Estadual Campo-Grandense, depois Colégio Estadual Campo-Grandense, sendo conhecido simplesmente como Colégio Estadual até receber o nome de sua fundadora. Em 1954 foi inaugurado o edifício onde funciona até hoje, projeto encomendado a Oscar Niemeyer pelo então governador para o Colégio Maria Leite de Corumbá, e duplicado em Campo Grande (Arruda, 1999).

A fundação do primeiro ginásio público na cidade foi justificada porque muitas famílias não teriam condição de pagar para que seus filhos ampliassem sua escolaridade. Com um ginásio público, o único obstáculo seria o "exame de admissão": aparentemente, a disputa por uma posição social deslocava-se das posses da família para o terreno da capacidade individual. ${ }^{12}$

É razoável supor que, como em outras cidades do país, essa possibilidade alterou a cultura escolar da cidade, afetando inclusive o ensino nas escolas par-

${ }^{11}$ É recorrente, em depoimentos e documentos da época, a importância atribuída à influência das professoras cuiabanas na história da educação em Campo Grande, na primeira metade do século XX (Araújo, 1997).

12 A percepção de que o exame de admissão era um obstáculo levou o governador Arnaldo Estevão de Figueiredo a propor, em 1948, a criação de um curso de admissão para preparar alunos da $4^{\mathrm{a}}$ série primária para realizarem esse exame, afirmando: “O curso é gratuito e se destina aos filhos dos funcionários públicos estaduais e de operários de modestos proventos..." (Alves, 1998, p. 144). ticulares, e que a escola em questão tenha se tornado uma referência de educação mesmo para as escolas mais antigas, podendo ser considerada a referência mais importante para iniciar a análise da cultura escolar em Campo Grande.

Assim como em Belo Horizonte a constituição do espaço físico dos grupos escolares como espaço social da cidade (Faria Filho, 1996) é um dos traços da cultura escolar da cidade, a mudança da escola Maria Constança do prédio do Joaquim Murtinho para um prédio projetado por Oscar Niemeyer, considerado pelos historiadores da arquitetura regional como o marco da arquitetura moderna local (Arruda, 2000, p. 29), provocou alterações na vida da cidade de Campo Grande, razão pela qual o estudo de sua cultura escolar não pode deixar de passar pela análise da arquitetura dessa escola.

No caso do edifício do Colégio Maria Constança, chama particularmente a atenção o fato de ter sido um projeto encomendado para a Escola Maria Leite, em Corumbá, duplicado em Campo Grande e construído num dos vazios da cidade (Ebner, 1999), entre o núcleo central e o Bairro Amambaí, primeiro bairro da cidade, onde residiam os operários que tinham trabalhado nas obras dos quartéis, e onde se instalou a Vila Militar. Segundo a autora, a legislação sobre ocupação urbana, de 1941, reflete tanto a segmentação das funções urbanas quanto das classes sociais.

As instituições não podem ser analisadas isoladamente porque, no decorrer de suas histórias, se estabelece uma espécie de diálogo entre elas, diálogo considerado mais do que uma troca de fala entre os interlocutores, "como um processo de autoconhecimento e de conhecimento do outro, um exercício de alteridade para a consciência de si e do outro" (Meserani, 1998, p. 66-67). A gênese de uma escola está, portanto, entrelaçada à gênese de várias outras, contemporâneas ou não. Assim, por exemplo, quando na cidade de Campo Grande foi fundado um ginásio estadual, já existiam três particulares. Realizouse, então, um diálogo interinstitucional, cujos efeitos sobre cada um dos estabelecimentos expressaram-se em suas práticas. 
Quando a diretora desse ginásio estadual, a professora Maria Constança, revela em entrevista que

Se um aluno se recusava a usar o uniforme, ou se comportava mal, o castigo eram as cópias. Depois vinham as suspensões e por último as transferências. Felizmente nunca expulsei um aluno. Quando ele se tornava inconveniente, incapaz de viver bem com os colegas, depois de chamá-lo inutilmente para admoestações e conselhos, dava-lhe a guia de transferência, que lhe permitia procurar outro estabelecimento de ensino, sem interromper os estudos. (Machado apud Rosa, 1990, p. 65)

Cabe uma pergunta: que outro estabelecimento? Certamente uma outra escola da cidade, cuja cultura permitia aceitar alunos como esses.

Conversas como essa provavelmente serão encontradas na análise das práticas escolares em geral, dos métodos de ensino, dos livros adotados, dos exames e das provas, possibilitando a reconstituição da história da cultura escolar da cidade de Campo Grande no período estudado e da relação entre a história da cidade e a história da escola.

EURIZE CALDAS PESSANHA, doutora em educação pela Universidade de São Paulo, é professora do Departamento de Educação da Universidade Federal de Mato Grosso do Sul e do Programa de Pós-graduação em Educação da mesma universidade. Publicou: Ascensão e queda do professor (São Paulo: Cortez, 1994; $3^{\text {a }}$ ed., 2001) e, em co-autoria, História da cultura escolar através dos exames: o caso dos exames de admissão ao ginásio (19391971), na Revista Intermeio (2002, $\mathrm{n}^{\circ} 16$, v. 8, p. 4-15). E-mail: eurizep@hotmail.com

MARIA EMÍLIA BORGES DANIEL, doutora em lingüística pela Universidade de São Paulo, é professora do Departamento de Letras do Centro de Ciências Humanas e Sociais e dos Programas de Mestrado em Educação e em Letras da Universidade Federal de Mato Grosso do Sul. Publicou, em co-autoria, História da cultura escolar através dos exames: o caso dos exames de admissão ao ginásio (1939-1971), na Revista Intermeio (2002, nº 16, v. 8,p.4-15).E-mail: mariaemi@nin.ufms.br
MARIA ADÉLIA MENEGAZZO, doutora em teoria literária e literatura comparada pela Universidade Estadual Paulista, é professora do Departamento de Letras do Centro de Ciências Humanas e Sociais e dos Programas de Mestrado em Educação e em Letras da Universidade Federal de Mato Grosso do Sul. Publicou em co-autoria: Alquimia do verbo e das tintas nas poéticas de vanguarda (Campo Grande: Editora da UFMS, 1992); Memória da arte em MS (Campo Grande: Editora da UFMS, 1993); Estudos de linguagem: inter-relações e perspectivas (Campo Grande: Editora da UFMS, 2003).E-mail: menmar@nin.ufms.br

\section{Referências bibliográficas}

ALVES, Gilberto L., (1984). Educação e história em Mato Grosso: 1719-1864. Campo Grande: Editora da UFMS. (Publicações UFMS, v.1).

ALVES, Laci M. A., (1998). Nas trilhas do ensino; educação em Mato Grosso: 1910-1946. Cuiabá: Editora da UFMT.

ARAÚJO, Carla B. Z. M., (1997). O ensino de didática na década de 30, no sul de Mato Grosso: ordem e controle. Dissertação de mestrado. Programa de Pós-graduação em Educação, Centro de Ciências Humanas e Sociais da Universidade Federal de Mato Grosso do Sul.

ARRUDA, Ângelo, (1999). Arquitetura em Campo Grande. Campo Grande: Editora da Uniderp. , (2000). A difusão da arquitetura moderna brasileira em Campo Grande: 1950-1980. Ensaios e ciência, Campo Grande, Editora da Uniderp, v. 4, n 3, p. 25-54.

BARROS, Maria C. L. de, (2000). A história da disciplina geografia nas décadas de 1930 e 1940: expressão da fisionomia do Estado. Dissertação de mestrado. Programa de Pós-graduação em Educação, Centro de Ciências Humanas e Sociais da Universidade Federal de Mato Grosso do Sul.

BITTAR, Marisa, (1999). Geopolítica e separatismo na elevação de Campo Grande a capital. Campo Grande/MS: Editora da UFMS.

BITTAR, Marisa, FERREIRA JR., Amarilio, (1999). De freguesia a capital: 100 anos da educação em Campo Grande. In: Campo Grande: 100 anos de construção. Campo Grande/MS: Matriz Editora, p. 195-236.

CANDIDO, Antonio, (1989). Educação pela noite. São Paulo: Ática. 
(1964). A estrutura da escola. In: PEREIRA, Luiz,

FORACCHI, Marialice M. Educação e sociedade. São Paulo:

Nacional, p. 107-128.

CARVALHO, Marta M., NUNES, Clarice, (1990). A formação das almas: o imaginário da República no Brasil. São Paulo: Companhia das Letras.

, (1993). Historiografia da educação e fontes. Cadernos ANPEd, Porto Alegre, Associação Nacional de PósGraduação e Pesquisa em Educação, nº 5, p. 7-64.

CERTEAU, Michel de, (1995). A cultura no plural. Campinas: Papirus. Tradução de Enid Abreu Dobránszky.

, (1998). A invenção do cotidiano: artes de fazer. v. 1, $4^{\mathrm{a}}$ ed. Petrópolis: Editora Vozes. Tradução de Ephraim Ferreira Alves. CHERVEL, A., (1990). História das disciplinas escolares: reflexões sobre um campo de pesquisa. Teoria e Educação, Porto Alegre, Panonica, no 2, p. 177-229.

CORRÊA, Valmir Batista, (1995). Coronéis e bandidos em Mato Grosso: 1889-1943. Campo Grande: Editora da UFMS.

CORREIA FILHO, Virgílio, (1969). História de Mato Grosso. Rio de Janeiro: MEC / Instituto Nacional do Livro.

DANIEL, Maria Emília Borges, (2001). Uma história da disciplina português no ensino normal: 1930-1940. Tese de doutorado. Programa de Pós-Graduação em Lingüística, Faculdade de Filosofia, Ciências e Letras da Universidade de São Paulo.

DE DECCA, Edgar, (1988). O silêncio dos vencidos. São Paulo: Brasiliense.

EBNER, Íris de Almeida R., (1999). A cidade e seus vazios. Investigação e proposta para os vazios de Campo Grande. Campo Grande: Editora da UFMS.

FARIA FILHO, Luciano Mendes de, (1996). Conhecimento e cultura na escola: uma abordagem histórica. In: DAYRELL, Juarez (org.). Múltiplos olhares sobre educação e cultura. Belo Horizonte: Editora da UFMG. p. 127-193.

FELIZ, Júlio, (1998). Consonâncias e dissonâncias de um canto coletivo: a história da disciplina canto orfeônico no Brasil. Dissertação de mestrado. Programa de Pós-graduação em Educação, Centro de Ciências Humanas e Sociais da Universidade Federal de Mato Grosso do Sul.

FORQUIN, Jean-Claude, (1993). Dois pontos de vista opostos sobre a escola e a cultura: Williams e Bantock. In: FORQUIN, J.-C. Escola e cultura: as bases sociais e epistemológicas do conhecimento escolar. Porto Alegre: Artes Médicas, p. 29-54.
GEERTZ, C., (1978). A interpretação das culturas. Rio de Janeiro: Zahar.

GVIRTZ, Silvina, (1995). El discurso escolar a traves de los cuadernos de clase: Argentina 1930-1990. Tese de doutorado. Universidad Nacional de Buenos Aires.

HAMILTON, David, (2001). From dialectic to didactic. Trabalho apresentado no Seminário A Virada Instrucional. São Paulo: Pontifícia Universidade Católica (mimeo.).

HÉBRARD, Jean, (2001). Por uma bibliografia material das escritas ordinárias: o espaço gráfico do caderno escolar (França séculos XIX e XX). Revista Brasileira de História da Educação, Campinas, ano 1, v. 1, p. 115-143.

HERTZBERGER, Herman, (1996). Lições de arquitetura. São Paulo: Martins Fontes. Tradução de Carlos Eduardo Lima Machado.

IANNI, Otávio, (1989). Estado e capitalismo. $2^{\text {a }}$ ed. São Paulo: Brasiliense.

JOSGRILBERT, Maria de Fátima V., (1998). A história da educação moral e cívica: um álbum de fotografias da sociedade brasileira. Dissertação de mestrado. Programa de Pós-graduação em Educação, Centro de Ciências Humanas e Sociais da Universidade Federal de Mato Grosso do Sul.

JULIA, D., (2001). A cultura escolar como objeto histórico. Revista Brasileira de História da Educação, Campinas, $\mathrm{n}^{\circ} 1$, p. $9-45$.

MARCÍLIO, Humberto, (1963). História do ensino em Mato Grosso. Cuiabá: Secretaria de Educação, Cultura e Saúde do Estado.

MENEGAZZO, Maria Adélia, (2001). Cultura e língua portuguesa. Trabalho apresentado no I Encontro Nacional de Estudos da Linguagem. Campo Grande: UFMS (mimeo.).

MESERANI, Samir, (1998). O intertexto escolar. Sobre leitura, aula e redação. $2^{\mathrm{a}}$ ed. São Paulo: Cortez.

PESSANHA, Eurize C., (1994). Ascensão e queda do professor. São Paulo: Cortez (Coleção Questões da Nossa Época, v. 34). (2000). Os primeiros concursos de seleção de professores: a construção da ordem sem didática. In: OSÓRIO, Antônio C. do N. (org.). Registros de educação. Campo Grande: Editora da UFMS, p. 103-124. , (2003). Perspectivas para a história das disciplinas escolares. In: SILVA, Denize E. G., LARA, G. M. P., MENEGAZZO, Maria Adélia. Estudos de linguagem. Inter- 
relações e perspectivas. Campo Grande: Editora da UFMS, p. 71-82.

PINEAU, Pablo, (1999). Premisas básicas de la escolarización como construcción moderna que construyó a la modernidad. Revista de Estudios del Curriculum, Barcelona/Espanha, v. 2, $\mathrm{n}^{\mathrm{o}} 1$, p. 39-61.

RAUBER, Pedro, (1999). A disciplina prática de ensino como reveladora da história da formação do professor primário no Brasil. Dissertação de mestrado. Programa de Pós-graduação em Educação, Centro de Ciências Humanas e Sociais da Universidade Federal de Mato Grosso do Sul.

RODRIGUES, Maria Benício, (1988). Educação escolar como instrumento de medição na relação Estado/povo: a reforma mato-grossense em 1910 - fase de implantação. Dissertação de mestrado em Filosofia da Educação. Pontifícia Universidade Católica de São Paulo.

ROMANELLI, Otaíza de Oliveira, (1983). História da educação brasileira. $4^{\text {a }}$ ed. Petrópolis: Vozes.

ROSA, Maria da Glória Sá, (1990). Memória da cultura e da educação em Mato Grosso do Sul. Campo Grande: Editora da UFMS.

SABOYA FILHO, E. G., (1993). Mato Grosso e a Reforma Educacional Pedro Celestino (1910): produto histórico do imperialismo. Dissertação de mestrado. Programa de Pós-graduação em Educação, Centro de Ciências Humanas e Sociais da Universidade Federal de Mato Grosso do Sul.

SILVA, Fabiany de Cássia T., (2003). As relações entre ensino, aprendizagem e deficiência mental desenhando a cultura escolar. Tese de doutorado. Pontifícia Universidade Católica de São Paulo.

SPOSITO, Marília, (1984). O povo vai à escola. A luta popular pela expansão do ensino público em São Paulo. São Paulo: Loyola. , (1993). A ilusão fecunda. A luta por educação popular nos movimentos populares. São Paulo: Hucitec/USP.

VALENTE, Wagner Rodrigues, (2001). Exames de admissão ao ginásio. 3 CD-ROM. São Paulo: PUC/SP, Programa de Estudos Pós-Graduados em Educação Matemática.

VIÑAO-FRAGO, Antonio, (2000). El espacio y el tiempo escolares como objeto histórico. Contemporaneidade e educação (Temas de história da educação). Rio de Janeiro: Instituto de Estudos da Cultura da Educação, ano 5, nº 7, p. 93-110.

VIÑAO-FRAGO, A., ESCOLANO, A., (1998). Currículo, espaço e subjetividade: a arquitetura como programa. Rio de Janeiro: DP\&A. Tradução de Alfredo Veiga-Neto.

WILLIAMS, R., (1992). Cultura. Rio de Janeiro: Paz e Terra.

Recebido em outubro de 2003

Aprovado em abril de 2004 
self-formation, which allow them to

reflect on their practice, the creation of spaces for exchange and conviviality in which individuals can exercise criticality, creativity and a strengthening of the relations between practiceltheory/practice, promoting the autonomous and systematic exercise of their actions, knowledge and powers.

Key-words: adult and youth education; formation of teachers; between-places

Lúcia Velloso Maurício

\section{Literatura e representações da} escola pública de horário integral $\mathrm{O}$ artigo apresenta o confronto entre $\mathrm{o}$ que se depreende da literatura produzida entre 1983 e 2001 sobre a escola pública de horário integral e a representação social que usuários e trabalhadores construíram sobre este tema. Após análise temática da literatura pertinente, realizou-se pesquisa de campo em quatro Centros Integrados de Educação Pública (CIEP) de $1^{\mathrm{a}}$ a $4^{\mathrm{a}}$ série, localizados em bairros populares, para identificar a representação social construída por alunos, pais, professores e funcionários. Nem todas as questões colocadas pela literatura foram contempladas no campo. Entretanto, ficou evidenciada a existência de duas óticas distintas a respeito da função social desta escola e dos fatores mobilizadores para sua demanda. De um lado, a representação dos professores, centrada na necessidade do aluno como justificativa para essa escola, assemelha-se aos argumentos encontrados na literatura. De outro lado, a representação dos pais e alunos, centrada na satisfação, contempla as idéias de lazer, futuro e educação.

Palavras-chave: escola pública de horário integral; representação social; necessidade $x$ satisfação

\section{Literature and representations} concerning full-time public schooling This article compares the literature produced between 1983-2001 on full- time public schooling and the social representation that users and workers formed about it. After analysing the main themes of the relevant literature, four Integrated Centres of Public Education (CIEP) were selected, in working-class districts, in order to identify the social representations created by their students, parents, teachers and administrative staff.

Although some of the questions raised by the literature could not be verified, the research indicated the existence of two different social representations about the full-time public school and the demand for it. One of them was the teachers'view, based on the needs of children to justify the maintenance of these schools, which was similar to the arguments found in the literature. The other was the social representation of parents and school children and was formed around the notion of satisfaction, contemplating the ideas of leisure, future and education.

Key-words: full-time public school; social representation; needs $\mathrm{x}$ satisfaction

Eurize Caldas Pessanha, Maria Emília Borges Daniel e Maria Adélia Menegazzo

Da história das disciplinas escolares à história da cultura escolar: uma trajetória de pesquisa

Este texto reflete sobre a trajetória que o grupo de pesquisa Professores e Disciplinas Escolares da Universidade Federal de Mato Grosso do Sul vem percorrendo e sobre como, partindo de pesquisas sobre a história das disciplinas escolares, o grupo chegou ao estudo da história da cultura escolar. Para essa reflexão, são analisados os pressupostos do campo de investigação conhecido como "história das disciplinas escolares", conforme Chervel, e os conceitos de cultura e cultura escolar, de acordo com Wiliams, Forquin, Julia, Faria Filho, Viñao-Frago e Escolano. O artigo argumenta que a investigação sobre a cultura escolar de uma determinada escola pode conduzir à reconstituição da história da cultura escolar de uma cidade.

Palavras-chave: cultura escolar; currículo; disciplinas escolares

From the history of school subjects to the history of school culture: a research trajectory

This text is a reflection on the trajectory that a research group on "Teachers and School Subjects", from the Federal University of Mato Grosso do Sul, has been pursuing and on how it arrived at the study of history of school culture, starting from research into the history of school subjects. For this reflection we analyse presuppositions from the field of investigation known as "history of school subjects", according to Chervel, and concepts of culture and school culture, as posited by Williams, Forquin, Julia, Faria Filho, ViñaoFrago and Escolano. We argue that research into the school culture of a determined school can lead to the reconstitution of the history of school culture in a specific city.

Key-words: school culture;

curriculum; school subjects

Antonio Miguel e outros

A educação matemática: breve histórico, ações implementadas e questões sobre sua disciplinarização Este trabalho foi elaborado em tópicos autônomos para discutir a configuração da educação matemática como área de pesquisa e, num panorama histórico, expõe e analisa como têm sido implementados, efetivamente, esforços para sua consolidação no Brasil. A partir da apresentação de alguns elementos relativos à emergência e à organização da pesquisa em educação matemática no panorama internacional (D'Ambrósio), ele passa a esboçar as motivações e estran- 